\title{
Short segment versus long segment posterior pedicular fixation of thoracolumbar fracture
}

\author{
Hayder A. Alhemiary* \\ Dhuha F. Almayoof**
}

\author{
FICMS \\ ABHS
}

\section{$\underline{\text { Abstract: }}$}

Background: Fracture dislocation at the junction between thoracic and lumber segments of spinal column by direct or indirect high energy force which is usually managed with more than three vertebral level fixation. Short segment stabilization have a wide range of benefits including length of time utilized for surgical intervention, reduce functional and psychological disability postoperatively and local surgical site complications.

Fac Med Baghdad 2017; Vol.59, No.3 Received: June 2017 Accepted: Aug. 2017

Objective: Evaluate the efficacy of posterior short segment pedicle stabilization in T-L fracture clinically and radiologically. Also to compare outcome of pedicle fixation by long segment and short segment an finally we try to insert at least one screw in the fracture vertebra to strengthen the stabilization in case of short segment stabilisation.

Patients and Method: This is a prospective study of 40 patients operated in medical city from Jan. 2013 to Dec. 2015.complaining from T-L fracture (T12, L1, L2) due to any type of trauma. A total of 17 of the patients (13 male and 4 female) underwent long segment fixation (group A) whereas 23(15 male and 8 female) of those patients have short segment fixation (group B). Long segment fixation includes two levels above and one or two level below with or without single screw placed in the vertebra that is broken. While short fixation involving vertebra above and vertebra below the fracture one.

Results: In tis prospective male commonly involved with the mean age 35-40 years in both groups, also most common involved vertebrae was 1st lumber. According to Modified Mcnab criteria, good result acquired by most of the patients, and using radiological Cobb angle evaluation significant loss of correction occur.

Conclusions: Short segment fixation in Thoracolumar region as effective as long segment. Short segment fixations are low coast with little complications at surgical site and need less blood replacement with less restriction of movement at the thoracolumbar junction.

Keywords: Thoracolumber vertebrae, fracture, short segment, long segment, fixation, intermediate screw.

\begin{abstract}
Introduction:
Fracture dislocation at the junction between thoracic and lumber segments of spinal column by direct or indirect high energy force which is usually managed with more than three vertebral level stabilization1.More than half of thoracolumber (T-L) vertebral spine trauma is a burst fracture2.Progressive neurological deficit deterioration ,incomplete neurological affection, kyphotic angulations of more than $250-30 \mathrm{o}$, also more than half lost of vertebral body height and $40 \%$ or more of the canal narrowing, all are an indications for as early as possible surgical intervention 3. Posterior vertebral approach is a common surgical modality utilized to treat a wide variety of pathological degenerative, high energy traumatic and malignant neoplastic pathologies in the T-L segment4.This posterior approach achieve prevention and correction of kyphotic deformity, fixation and stabilization of all three spinal column and subsequently decompression of stenosed spinal canal by vertebral positioning and fracture distraction4.Short segment stabilization have a wide *Dept. of neurosurgery, Alshaheed Ghazi, Medical city.halhemiary@yahoo.com.
**Radiologist, Radiology department, Alshaheed Ghazi, Medical city.

range of benefits including length of time utilized for surgical intervention, functional and psychological disability postoperatively and local surgical site complications whereas the long segment procedure may result in limitation of patient movement and increase pressure loading on segment adjacent to it 4.In some cases of anterior column disruption, short segment fixation can not be sufficient to ensure possible adequate stability5. There are many methods to evaluate the outcome clinically and radiologically for clinical follow up Modified Mcnab criteria is more easy to use and applicable for almost all of the patients6. According to these criteria the patients who regain his activity without restriction or significant pain have excellent score while for those how have back pain that sometimes limit his ability for normal daily living and work have score good, while patients that have pain with limitation of activity that necessat change their lifestyle although their ability to function have been improved given score fair, finally patients that need more operative interventions or don't have enough improvement in daily living activity given score poor 6 . While for radiological assessment after operation Cobb Angle method used widely7. (fig.1) 

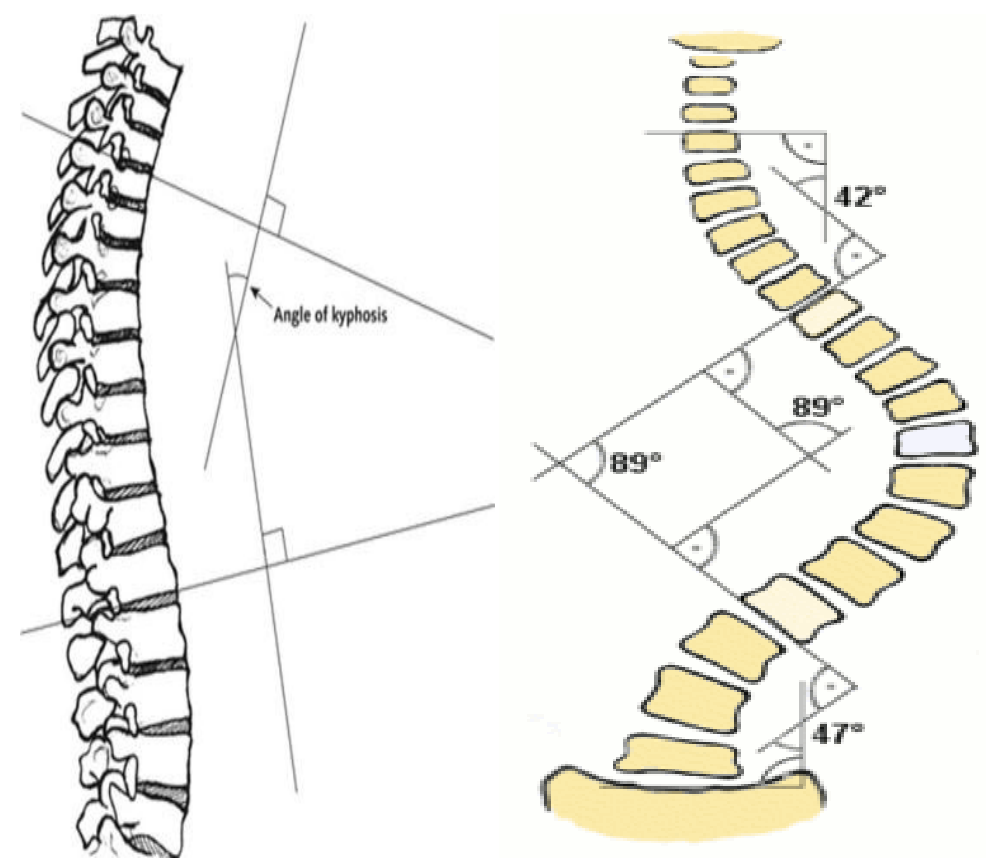

Fig.1 Cobb angle evaluation oscoliossis.

The Cobb angle, have its name according to the surgeon from America in the orthopedic field called Robert Cobb (1903-1967), formerly it's used to evaluate deformity shown in X-ray coronal film while they try to classify scoliosis. Later it is used to evaluate lateral X-ray plane abnormality, mainly in the condition of injury to the spinal column at the junction of thoracic and lumber region. In cases where spinal fracture occur using lateral X-ray view of the spine, the Cobb angle is the measurement of the angle between two line the above one parallel to the upper border of the vertebral end plate of vertebra above the fractured one while the lower line parallel to the inferior border of the end plate of the vertebra below fracture one.7, 8, 9

\section{Patients and Method:}

This is a prospective study of 40 patients operated in medical city from Jan. 2013 to Dec. 2015.complaining from T-L fracture (T12, L1, L2) due to any type of trauma. In each we did X-ray and CT scan to the affected region before and after surgery to see the morphology of the fracture and to have an idea about any potential complication related to the placement of screw insertion.MRI also done pre-operatively to assess for any canal encroachment and abnormal signal in the spinal cord and other soft tissue. A total of 17 of the patients (13 male and 4 female) underwent long segment fixation (group A) whereas 23(15 male and 8 female) of those patients have short segment fixation (group B).All patients underwent posterior pedicle screw fixation( in the usual conventional way regardless of the number of the vertebrae fixed) and reduction under $\mathrm{C}$-arm monitoring. Long segment fixation includes two levels above and one or two level below with or without single screw placed in the vertebra that is broken. While fixation involving vertebra above and vertebra below the fracture one represent short fixation and if fractured vertebrae not severely distracted single screw may be inserted in. Criteria used for short segment stabilization are single vertebra fracture, spinal spondylolesthesis grade one and two, and kyphotic angle not significantly changed (Cobb angle). All the patient followed postoperatively clinically using the modified Mcnab criteria and radiologically using the Cobb method immediately after operation and at interval of 3, 6, 12 months postoperatively. All study participants provided informed consent.

\section{Result:}

Table1. Patients' distribution

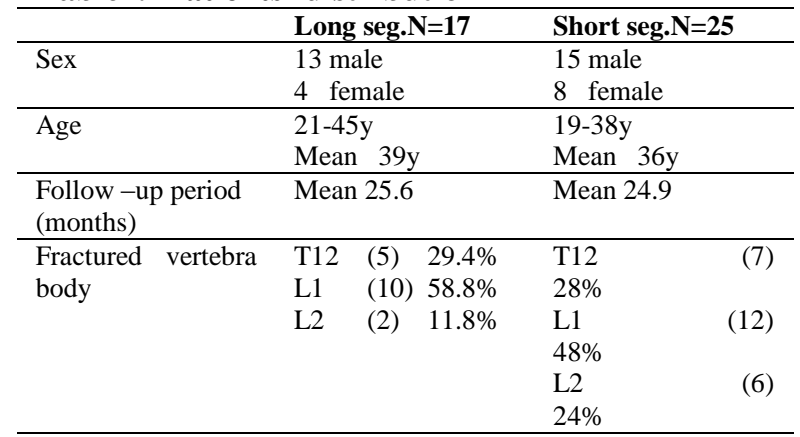

Table2. Assessment of clinical outcome according to the modified Mcnab criteria.

\begin{tabular}{lllll}
\hline & $\begin{array}{l}\text { Long-segment } \\
\text { group (N=17) }\end{array}$ & \multicolumn{2}{l}{$\begin{array}{l}\text { Short-segment } \\
\text { group (N=25) }\end{array}$} \\
\hline Excellent & 4 & $23.5 \%$ & 5 & $20 \%$ \\
\hline Good & 9 & $53 \%$ & 18 & $72 \%$ \\
\hline Fair & 3 & $17.6 \%$ & 1 & $4 \%$ \\
\hline Poor & 1 & $5.9 \%$ & 1 & $4 \%$ \\
\hline
\end{tabular}


Table3. Mean of kyphotic angle measured using the Cobb method.

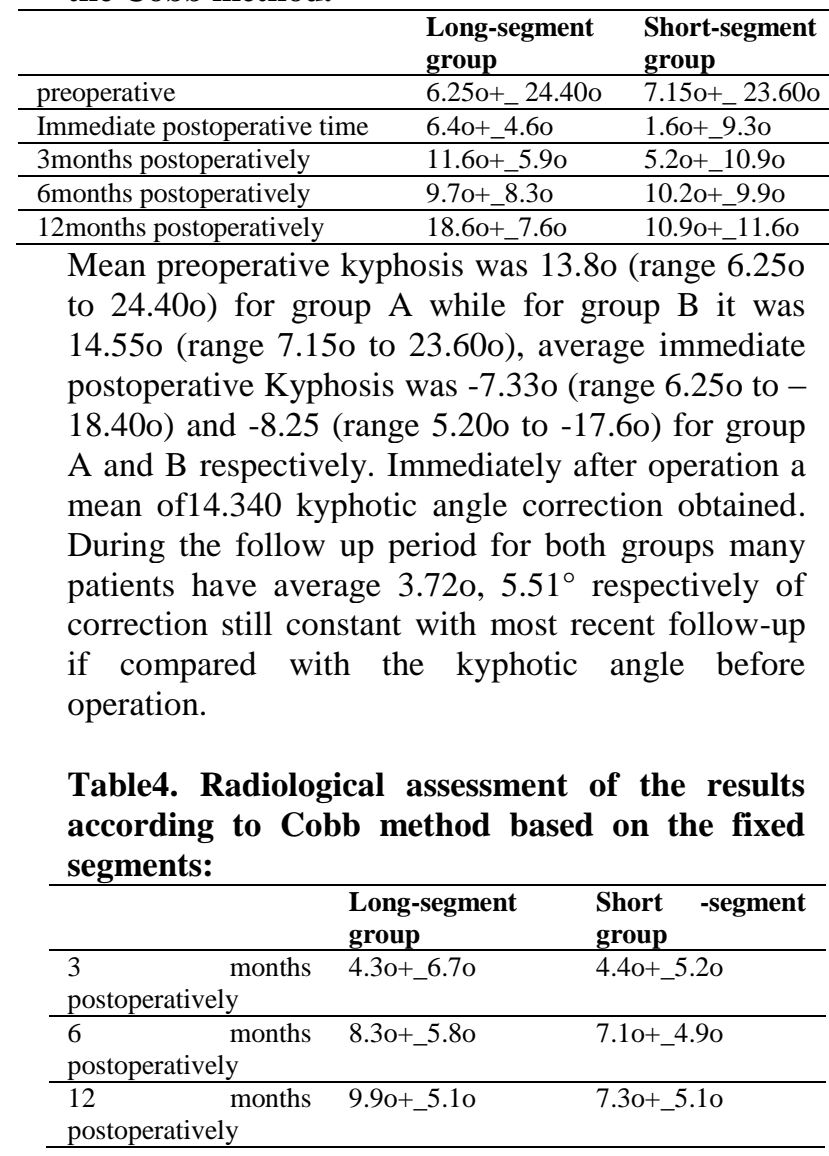

During the follow up period for both groups many patients have significant loss of their correction $\left(11.51^{\circ}\right)$ and $(9.510)$ respectively.

\section{Discussion:}

Since the introduction of transpedicular screw fixation and internal fixation, short segment fixation of the thoracolumaber burst popular in use. Although this approach have many advantages like low coast, less pain, less surgical site complications(minimal iatrogenic muscles trauma and blood loss),functional deterioration and short time of surgery but it has the disadvantage of loss the reduction obtained in addition to screw failure 10 . Screw failure happened either due to itself failure (weeks may be months later especially in young patients with strong dense bone) or bone loosening10. Some surgeon add one screw in the fractured vertebra named intermediate screw as a part of short segment fixation that will increase strength of fixation by reducing distance crossed by the rod which spin between two points of fixation 10 . In this study the most gender affected by this kind of trauma are male, young patients in both groups which is attributed to the cause of trauma like war injury among soldiers, high places workers and motorcycle drivers (table 2). Jin-Woo Hur et. al. and Ling Wang et. al.

Also find that this type of fractures occurs highly among male, young patients 3,11, whereas Umut Canbek et. al. and Jonathan-James et. al. found no much differences in the gender affection although mainly affect young and middle age patients 10,12 In our study we found that the more affected vertebra was L1 reaching up to $58 \%$ in group A and $48 \%$ in the other group(table 2). Jin-Woo et al. also report the same result 3 . (fig.2)

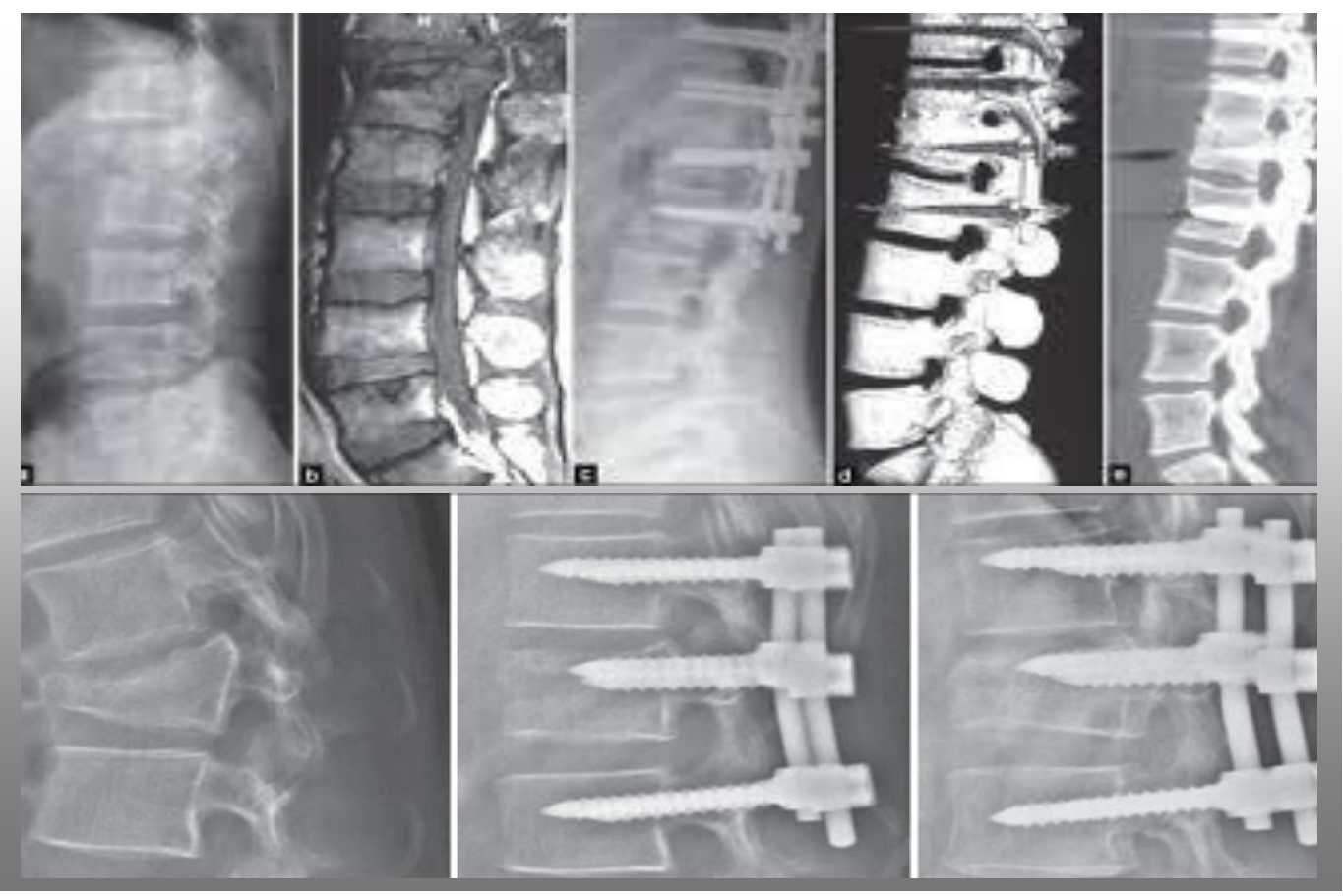

Fig.2 X-ray for two patients from both groups 
Clinically after operation and according to Macnab criteria good result obtained in about $53 \%$ in group A while $72 \%$ in group B while excellent result come next in both groups account for $23 \%$ and $20 \%$ respectively. Fair result was high in group A reaching up to $17 \%$ while its $4 \%$ for fair and poor outcome in group B (table 3 ).

Jin-woo et al. also report the high percentage for Good score $(50 \%, 62 \%$ for group A and B respectively) and they found excellent result in group A $34 \%$ ) in comparison to $18.8 \%$ in group B while fair outcome $11.4 \%, 18.8 \%$ respectively for both group. Poor outcome was $2 \%$ for group A and was nil in other one3. However Jonathan-James et al. found that good clinical progress of patient's disability during whole time of follow up 12 . Tezeren et al. report little or no difference between both groups during clinical follow up 13. (Fig.3) In this study ,Immediately after operation long-segment group have better correction of the local kyphosis angle although associated with limitation of the motion segment in comparison with the shortsegment group(Table 4).Also short-segment achieve good correction of the lordotic angle postoperativly ( cob angle) in comparison to preoperative angle .

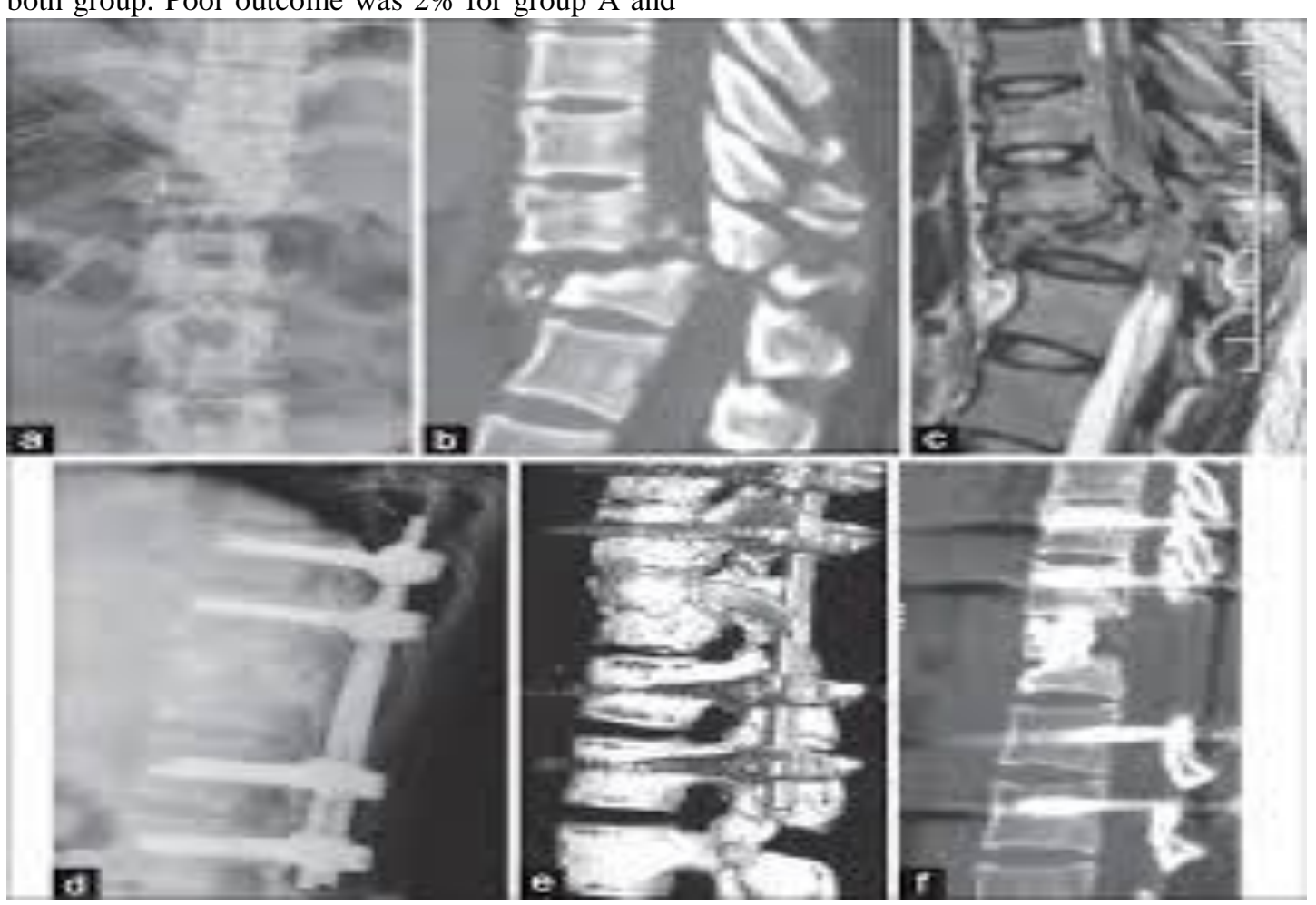

Fig.3 patient have L1 fracture treated by long segment stabilization

Directly after operation good kyphotic angle reduction in both groups obtaining mean postoperative angulations of saggital plane $\left(0.74^{\circ}\right.$ and 0.7550 ) if compared to the kyphotic angle ( $13.8^{\circ}$ and 14.550 respectively) pre-operatively which evaluated by the mentioned Cobb method. During the follow up period for both group many patients have significant loss of their correction $\left(11.51^{\circ}\right)$ and (9.510) respectively, while $3.720,5.51^{\circ}$ respectively of correction still constant with most recent followup if compared with the kyphotic angle before operation. All this means that there is no much difference in the radiological result for both group at immediate and during the follow up period. This result also achieved by Jin- Woo Hur et.al. Umut Canbek et. al. 3, 10 while Shang-Won et.al. Found that short segment fixation not strong enough as that for the long one14.

\section{Conclusions:}

Short segment fixation(including the fractured vertebrae) in Thoracolumar region as effective as long segment with good spinal canal restoration and correction of Kyphotic angle and may enhance the regaining of neurological function although better result achieved radiologically by long segment fixation while clinically are the same result. Short segment fixations are low coast with little complications at surgical site and need less blood replacement with less restriction of movement at the thoracolumbar junction. In short segment fixation intermediate screw inserted at the pedicle of fractured vertebrae is effective in the postoperative stability of the spinal column and prevent failure of the fixation.

\section{Authors' contributions:}

Dr. Hayder collect the patients and evaluate them clinically then after surgical decision taken, surgical intervention done by him and fallow them after home discharge.

Dr. Dhuha evaluates the patients radiologically and gives opinion about the stability and then accordingly the kind of surgery to be done weather short or long segment to be done. 


\section{References:}

1-Shang-Won $Y u, M D ;$ Kuo-Feng Fan, MD; IChuan Tseng. Surgical Outcome of Short-Segment fixation for thoracolumbar Fracture Dislocation. Chang Gung medd J 2002; 25:253-9.

2- Jonathan-james $t$ Eno, BSc, james L Chen, MD, and Morris m Mitsunaga, MD. Short Same-Segment fixation of Thoracolambar Burst Fractures. Hawai J Med Puplic Health, 2012 Jan; 71(1) : 19-22.

3- Jin- Woo Hur, Jong- Joo rhee ,Jong-Won Lee, Hyun-Koo Lee. A comparative analysis of efficacy of short-segment pedicle screw fixation with that of long-segment pedicle screw fixation for unstable thoracolumar spinal burst fractures. Clinical Medicin Research.Vol. 4, No 1, 2015, pp 1-5 , Doi; 10.11648/j.cmr. 20150401. 11

4- Shmidek \&Sweet: Operative Neurosurgical Technique : Vol 2 indications, method by Alfredo Quinones -Hinojosa P 2033.

5-Farrokhi MR, Razmkon A, Maghami Z, Nikoo Z. Inclusion of the fracture level in short segment fixation of thoracolumbar fractures. Eur Spine J. 2010 Oct;19(10):1651-6. doi: 10.1007/s00586-0101449-z. Epub 2010 May 21.

6-Macnab I. "negative disc exploration: an analysis of the cause of nerve root involvement in sixty-eight patients." J Bone Joint Surg (Am) 1971 ;53:891903.

7-Cobb JR. Outline for the study of scoliosis. The American Academy of Orthopedic Surgeons Instructional Course Lectures. Vol. 5. Ann Arbor, MI: Edwards; 1948.

8- Keynan, Ory; Fisher, CG; Vaccaro, A; Fehlings, MG; Oner, FC; Dietz, J; Kwon, B; Rampersaud, R; Bono, C; France, J; Dvorak, $M$ (Mar 1, 2006). "Radiographic measurement parameters in thoracolumbar fractures: a systematic review and consensus statement of the spine trauma study group." (PDF). Spine 31 (5): E156-65. doi:10.1097/01.brs.0000201261.94907.0d. PMID 16508540. Retrieved 15 December 2012.

9- Kado DM, Christianson L, Palermo L, SmithBindman $R$, Cummings SR, Greendale GA. Comparing a supine radiologic versus standing clinical measurement of kyphosis in older women: the Fracture Intervention Trial. Spine. 2006; 31:463-7.

10-Umut Canbek, Levent Karapinar, Ahmet Imerci.Posterior fixation of Thoracolumbar burst fractures: is it possible to protect one segment in the lumbar region. Eur J Orthop surg Traumatol (2014) 24;459-465.

11-Ling Wang et. al. Posterior short segment pedicle screw fixation and TLIF for the treatment of unstable Thoracolumbar numbar fracture .http://bmcmusculoskeletdisord.biomedcentral.com/a rticles/10.1186/1471-2474-15-40.

12-Jonathan-James T Eno, BSc, James L Chen, MD, and Morris $M$ Mitsuunaga, MD. Short sameSegment fixation of Thoracolumbar Burst Fractures. Hawai J Med Public Health 2012 Jan ; 71(1): 19. 22

13- Tezeren G, Kuru I, Posterior fixation of thoracolumbar burst fracture: Short-segment pedicle fixation versus Long-segment instrumentation. J. Spinal. Discord. Tech. 18:485488, 2005.

14- Shang-Won Yu,MD; Kuo-Feng Fan, MD; IChuan Tseng,MD; Yi-Lee Chiu, MD; Yeung-Jen Chen, MD, PhD; Wen-Jer Chen, MD,PhD: Surgical Outcome of short-Segment Fixation for Thoracolumbar Fracture Dislocation. hang Gung Med J 2002;25:253-9. 